\title{
SOLVENT EFFECT ON PROTONATION OF TPPS IN WATER-DMF MIXTURES
}

\author{
Ali Farajtabar ${ }^{*}$ and Mohammad Faeli \\ Department of Chemistry, Jouybar branch, Islamic Azad University, Jouybar, Iran
}

(Received December 18, 2014; revised May 20, 2016)

\begin{abstract}
The protonation of 5,10,15,20-tetrakis(4-sulfonatophenyl)porphyrin was investigated in aqueous solutions of N,N-dimethyformamide at $25^{\circ} \mathrm{C}$ and 0.1 mol.dm ${ }^{-3}$ sodium perchlorate. The solvent effect on value of protonation constant was examined by using the linear solvation energy relationship concept. The value of $\log K_{1}$, $\log K_{2}$ and $\log K_{\mathrm{t}}$ was correlated with the macroscopic (dielectric constant) and microscopic Kamlet-Taft parameters $\left(\alpha, \beta\right.$ and $\left.\pi^{*}\right)$ of binary mixtures. The solvent effects were analyzed in the terms of Kamlet, Abboud and Taft model (KAT). Multiple linear regression were used to find the contribution of the microscopic parameters containing $\alpha$ (hydrogen-bond acidity), $\pi^{*}$ (dipolarity/polarizability) and $\beta$ (hydrogen-bond basicity). It was found that $\alpha$ and $\beta$ were the most predominant descriptors. Also, relationship with reciprocal of dielectric constant was obtained based on Born's model, showing the significance of specific solute-solvent interactions. Therefore the hydrogen bonding interactions between solute and solvent components are mainly responsible for the change in protonation constants of 5,10,15,20-tetrakis(4-sulfonatophenyl)porphyrin in water- N,N-dimethyformamid binary mixtures.
\end{abstract}

KEY WORDS: Protonation, TPPS, Solvent effects, Aqueous mixture, DMF

\section{INTRODUCTION}

Various biological and industrial applications of porphyrins made them interesting compounds [1-3]. Among porphyrin derivatives, 5,10,15,20-tetrakis(4-sulfonatophenyl) porphyrin, TPPS, is well-known. TPPS is extensively used as photosensitizer for photodynamic therapy and tumors diagnosis in cancer treatment. Also it is suitable candidates for use as the models of electron transfer and artificial light harvesting devices to mimic photosynthetic organisms [4]. In these applications, properties such as large extinction coefficient in the red region of the visible wavelengths and high hydrophilicity play important role in the overall efficiency of TPPS. Physicochemical properties of TPPS help to discriminate between normal cells and abnormal ones, and lead to selective accumulation of photosensitizer in tumor target tissues. TPPS has capable to initiate a photochemical reaction by absorbing photons upon exposition to light at visible wavelength. Excited singlet oxygen is one of photochemical reaction product which is very aggressive and toxic for cellular tissues and will oxidize malignant cells [5]. Although the exact mechanism for photodynamic therapy of porphyrins in abnormal tissues is still not well known, numerous studies have confirmed its efficacy to be depend on the environmental characteristics and physicochemical properties of photosensitizer [6-9].

The free base TPPS $\left(\mathrm{H}_{2} \mathrm{tpps}^{4-}\right)$, Figure 1, can be protonated by one or two protons on pyrrolinic nitrogen's resulting to the mono $\left(\mathrm{H}_{3} \mathrm{tpps}^{3-}\right)$ and di-protonated $\left(\mathrm{H}_{4} \mathrm{tpps}^{2-}\right)$ species which have drastically different physicochemical properties such as aggregation and lipophilicity which lead to different cellular uptake and photodynamic effect $[10,11]$. As shown in some studies, protonation of photosensitizer compounds leads to higher cellular uptake [6,7]. It is clear that protonation brings about the redistribution of electron density in porphyrin core, which modifies characteristics of central pyrrolic nitrogen atoms, and also influence physicochemical and spectral properties of TPPS in solutions. Thus, in order to obtain a detailed knowledge about the nature of this compound, a complete evaluation of its acid-base characteristics and their dependence on environmental conditions are required.

*Corresponding author. E-mail: a_farajtabar@yahoo.com 


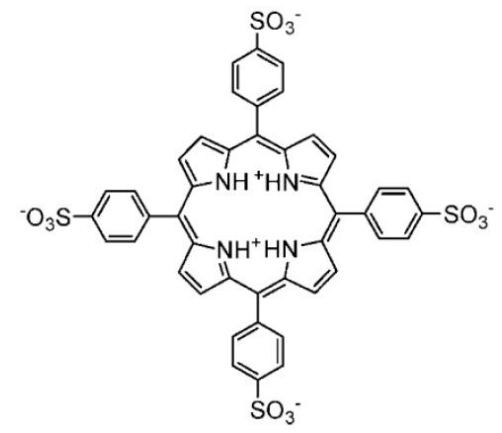

Figure 1. Molecular structure of diacidic form of 5,10,15,20-tetrakis(4-sulfonatophenyl) porphyrin.

In continuous of our previous studies on porphyrin [12-17], in this work the protonation constants of 5,10,15,20-tetrakis(4-sulfonatophenyl) porphyrin were determined by spectroscopic titration in binary mixtures of water with N,N-dimethylformamide, DMF, to examine the solvent dependence of its acid-base properties. Spectroscopic titration is a convenient way for accurate determination of equilibrium constants [18-20]. In this method, the spectral absorbances during titration are used to construct a matrix $\mathrm{R}$ of size $\mathrm{m} \times \mathrm{n}$ where $\mathrm{m}$ is the number of $\mathrm{pH}$ values in which absorbance are determined in $\mathrm{n}$ wavelengths. The absorbance data matrix $\mathrm{R}$ is decomposed into pure concentration, $\mathrm{C}$, and pure spectral profiles, $\mathrm{S}$, matrices by knowledge about the number of chemical species in protonation processes.

$\mathrm{R}=\mathrm{CS}+\mathrm{E}$

Where $\mathrm{C}(\mathrm{m} \times \mathrm{p}), \mathrm{S}(\mathrm{p} \times \mathrm{n})$ and $\mathrm{E}$ are matrix of pure concentration, pure spectral profiles and optimal residual error respectively. Here $p$ donates the number of absorbing species in the solution. The number of absorbing species is determined from factor analysis [21]. Rank analysis is performed by introducing $M$ as $(1 / n) R R^{t}$, where $R^{t}$ is transpose of $R$. The rank of $M$, $r_{M}$, is mathematically equal to the number of eigenvectors with corresponding none zero eigenvalues. However, because of experimental error, the number of absorbing species is equal or lower than $\mathrm{r}_{\mathrm{M}}$. To this problem, in factor analysis, the standard deviation of the absorbance, $\mathrm{SD}$, are calculated as a function of the number of none zero eigenvalues.

$\mathrm{SD}=\sqrt{\frac{\operatorname{tr}(\mathrm{M})-\sum_{i=1}^{j} a_{i}}{m-j}}$

Where $\operatorname{tr}(\mathrm{M})$ and $\mathrm{a}_{\mathrm{i}}$ are the trace and eigenvalue of component $\mathrm{i}$ of $\mathrm{M}$ matrix. Accordingly, the spectral change during titration is attributed to the number of absorbing species, which is consistent with the number of species during protonation equilibria. By this knowledge, Eq. 1 is solved using hard modeling multivariate curve fitting. By initial estimation of protonation constant, fitting starts by calculation of the concentration profile of absorbing species, matrix $\mathrm{C}$, based on the mass action law constraint in terms of known total concentration and $\mathrm{pH}$ values during titration. At the same time, matrix $\mathrm{S}$ is solved under non-negative absorptivity constraint for absorbing species. In the nonlinear least-squares fitting, iterative cycles go on until to find the best set of parameters (protonation constant and molar absorptivity of species) that result in a minimum of $\mathrm{E}$. 


\section{EXPRIMENTAL}

\section{Chemical and instrumentations}

Tetrakis(4-sulphonatophenyl)porphyrin sodium salt, $\mathrm{Na}_{4}\left[\mathrm{H}_{2} \mathrm{tpps}\right]$, of $98 \%$ purity was purchased form Aldrich. N,N-dimethylformamide, DMF, were obtained from Merck. Sodium perchlorate of $99.8 \%$ purity was from Merck and was dried under vacuum at room temperature for at least 72 hours before use. $\mathrm{NaOH}$ solution was prepared from a titrisol solution (Merck) and its concentration was determined by several titrations with a standard $\mathrm{HCl}$ solution. $\mathrm{HClO}_{4}$ (ACS grade, $70 \%$ ) was from Merck and was used as supplied. All aqueous mixtures were prepared from double-distilled water with a conductivity equal to $1.3 \pm 0.1 \mu \mathrm{ohm}^{-1}$.

The electromotive force was measured using a Jenway (model 3520) research potentiometer equipped with a combined $\mathrm{pH}$ electrode which consists of a glass electrode and a reference $\mathrm{Ag} / \mathrm{AgCl}$ electrode built into a single chamber.

Spectrophotometric measurements were performed on a UV-Vis Shimadzu 2100 spectrophotometer with a Pentium 4 computer and using thermostated matched $10 \mathrm{~mm}$ quartz cells. The measurement cell was of flow type. A peristaltic pump allowed circulation of the solution under study from the potentiometric cell to the spectrophotometric cell, so the absorbance and the emf of the solution could be measured simultaneously. To exclude carbon dioxide from the system, a stream of purified nitrogen was passed through a sodium hydroxide solution and then bubbled slowly through the reaction solution.

\section{Procedure}

Potentiometric titration was performed in water-DMF mixtures to calibrate the combined glass$\mathrm{pH}$ electrode according to Gran's method [22]. The combined $\mathrm{pH}$ electrode was modified by replacing its aqueous $\mathrm{KCl}$ solution with 0.01 mol.dm ${ }^{-3} \mathrm{NaCl}+0.09$ mol.dm $\mathrm{daClO}_{4}$ saturated with $\mathrm{AgCl}$ to reduce the liquid junction potential and drifts of electrode potential. The electrode was soaked for 15-20 min in water-organic solvent mixture before potentiometric measurements. All titrations were carried out in a $50 \mathrm{~mL}$ thermostated double-walled glass vessel. The standard potential of the cell, $E_{\text {cell }}^{o}$, was calculated by titration of $25 \mathrm{~mL}$ acidic solution of $\mathrm{HClO}_{4}\left(0.01 \mathrm{~mol}^{-\mathrm{dm}^{-3}}\right)$ with small addition of the sodium hydroxide solution $(0.1$ mol. $\left.\mathrm{dm}^{-3}\right)$. The cell potential, $E_{\text {cell }}$, is given by Eq. 3 during titration.

$E_{\text {cell }}=E_{\text {cell }}^{\circ}+k \log \left[\mathrm{H}^{+}\right]+\operatorname{klog} \gamma_{\mathrm{H}^{+}}+E_{\mathrm{LJ}}$

where $E_{\mathrm{LJ}}$ is the liquid junction potential, $k=2.303 R T / F$ in which $R, T$ and $F$ have the usual meaning, and $\gamma_{\mathrm{H}^{+}}$is the activity coefficient of hydrogen ion, respectively. The ionic strength of the solution is kept constant throughout titration process, therefore the activity coefficient of hydrogen ion is constant too. The non-ideality of solutions is then included in $k_{\mathrm{a}}$ (the specific constant of the potentiometric cell), and thus

$E_{\text {cell }}=k_{\mathrm{a}}+k \log \left[\mathrm{H}^{+}\right]$

with $k_{\mathrm{a}}$ being $E_{\text {cell }}^{\circ}+k \log \gamma_{\mathrm{H}^{+}}+E_{\mathrm{LJ}}$. Based on potentiometric titration, $k_{\mathrm{a}}$ and $\mathrm{k}$ were determined, and then used to convert the potential cell into $\mathrm{pH}$ in spectroscopic titration.

For spectroscopic titration, $25 \mathrm{~mL}$ of TPPS solution $\left(1.7 \times 10^{-6} \mathrm{~mol}_{\mathrm{dm}} \mathrm{dm}^{-3}\right)$ was titrated with 0.1 mol. $\mathrm{dm}^{-3} \mathrm{HClO}_{4}$ and $\mathrm{NaOH}$ solution in the same ionic strength and mole fraction of organic solvent $(0-95 \%$ organic solvent by $\mathrm{v} / \mathrm{v})$. Absorbance data were recorded against the cell potential. $\mathrm{pH}$ was calculated using Eq. 4. Finally, spectral data as a function of $\mathrm{H}^{+}$concentration were introduced into STAR program to calculate protonation constants [21]. All potentiometric and spectroscopic measurements were performed at $25{ }^{\circ} \mathrm{C}$ and constant ionic strength of 0.1 mol. $\mathrm{dm}^{-3}$ sodium perchlorate, and were repeated at least three times. 


\section{RESULTS AND DISCUSSION}

\section{Glass electrode calibration}

The combined glass-pH electrode was successfully calibrated in binary mixture by potentiometric titration. Typically, calibration curve is depicted for $50 \%(\mathrm{v} / \mathrm{v})$ in Figure 2 . As shown, a good linear equation was obtained; indicating the reliability of Eq. 4 for determination of $\mathrm{pH}$ in binary water-DMF mixtures, in addition, the experimental slope was very close to the theoretical Nernst' slope $\left(59.2 \mathrm{mV}\right.$ at $\left.25^{\circ} \mathrm{C}\right)$.

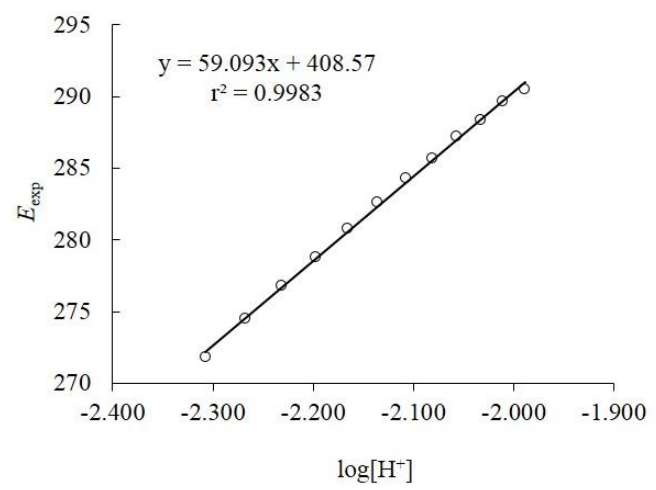

Figure 2. Calibration curve obtained from potentiometric titration for $50 \%(\mathrm{v} / \mathrm{v})$ at $25^{\circ} \mathrm{C}$ and 0.1 $\mathrm{mol} \cdot \mathrm{dm}^{-3} \mathrm{NaClO}_{4}$

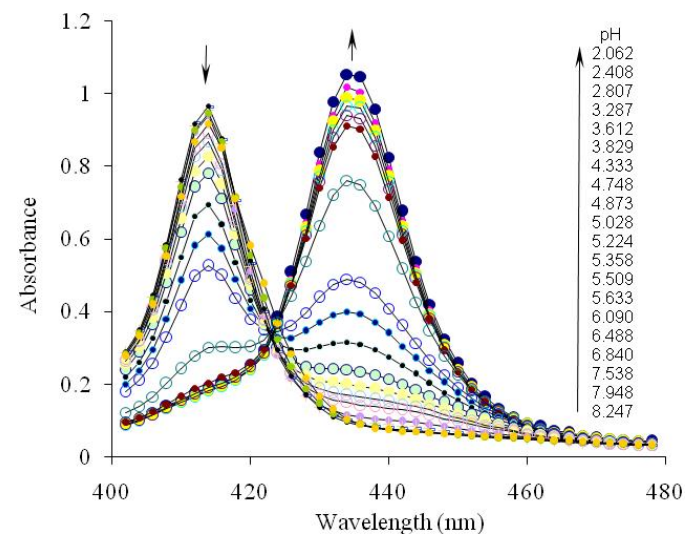

Figure 3. Absorption of TPPS at different wavelengths as a function of $\mathrm{pH}$ in water at $25{ }^{\circ} \mathrm{C}$ and $0.1 \mathrm{~mol} \cdot \mathrm{dm}^{-3} \mathrm{NaClO}_{4}$.

\section{Protonation constant of TPPS}

As shown in Figure 3, in aqueous solution, diacidic form of TPPS, $\mathrm{H}_{4} \mathrm{tpps}^{2-}$, has a maximum absorption spectrum band (the Soret band) around $435 \mathrm{~nm}$. These zwitterionic forms have a tendency to form J-aggregates which show a red shifted Soret band with respect to the monomer's ones [23]. However in this work no evidence of aggregation was found for studied concentration of TPPS $\left(1.7 \times 10^{-6} \mathrm{~mol} . \mathrm{dm}^{-3}\right)$ at different solvent mixture. When an acidic solution was gradually added to the alkali solution of TPPS, the Soret band shifted to higher wavelength

Bull. Chem. Soc. Ethiop. 2016, 30(3) 
upon protonation of TPPS core. According to these clear spectral changes, the protonation constant can be calculated by using a suitable data analysis model.

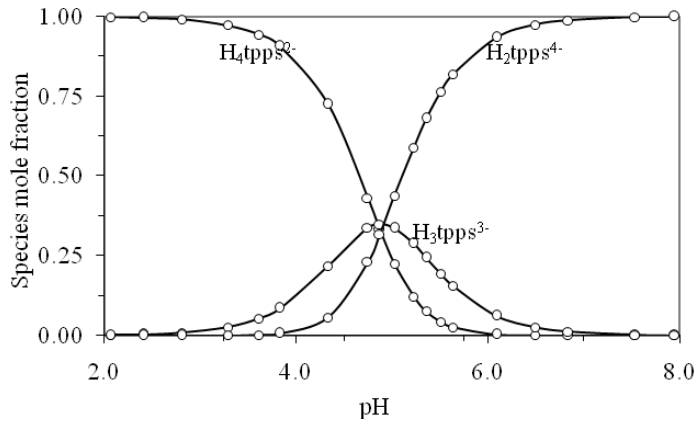

Figure 4. Distribution diagram of various species of TPPS in water at $25{ }^{\circ} \mathrm{C}$ and an ionic strength of $0.1 \mathrm{~mol} \cdot \mathrm{dm}^{-3} \mathrm{NaClO}_{4}$.

The protonation constants were calculated by nonlinear least squares fitting in STAR program environment using an input file including the spectral data in $0.5 \mathrm{~nm}$ intervals as a function of $\mathrm{H}^{+}$concentration [21]. Results are listed in Table 1 with the solvent parameters, dielectric constant $\left(\varepsilon_{\mathrm{r}}\right)$ and Kamlet, Abboud and Taft $\left(\alpha, \beta\right.$ and $\left.\pi^{*}\right)$ parameters which were extracted from the literature $[24,25]$. The first $\left(\mathrm{H}_{2} \mathrm{tpps} \mathrm{s}^{4-}+\mathrm{H}^{+} \rightarrow \mathrm{H}_{3} \mathrm{tpps}^{3-}\right)$, second $\left(\mathrm{H}_{3} \mathrm{tpps}^{3-}+\mathrm{H}^{+}\right.$ $\left.\rightarrow \mathrm{H}_{4} \mathrm{tpps}^{2-}\right)$ and overall protonation constant of TPPS $\left(\mathrm{H}_{2} \mathrm{tpps}^{4-}+2 \mathrm{H}^{+} \rightarrow \mathrm{H}_{4} \mathrm{tpps}^{2-}\right)$ were assigned by $\log K_{1}, \log K_{2}$ and $\log K_{\mathrm{t}}$, respectively. Results indicate that the second and first protonation are very close to each other and happen simultaneously. In Figure 4, the mole fraction distribution of various species of TPPS is shown in water as a function of $\mathrm{pH}$.

Table 1. Protonation constants of TPPS, KAT solvatochromic parameters and the dielectric constants in different water-DMF mixtures at $25^{\circ} \mathrm{C}$ and $0.1 \mathrm{~mol} \cdot \mathrm{dm}^{-3} \mathrm{NaClO}_{4}$.

\begin{tabular}{|c|c|c|c|c|c|c|c|}
\hline $\begin{array}{c}\text { DMF } \\
\%(\mathrm{v} / \mathrm{v})\end{array}$ & $\log K_{2}$ & $\log K_{1}$ & $\log K_{\mathrm{t}}$ & $\alpha$ & $\beta$ & $\pi^{*}$ & $\varepsilon_{\mathrm{r}}$ \\
\hline 0.0 & $4.854 \pm 0.031$ & $4.913 \pm 0.041$ & 9.767 & 1.17 & 0.47 & 1.09 & 79.50 \\
\hline 10 & $3.483 \pm 0.020$ & $3.964 \pm 0.010$ & 7.447 & 1.05 & 0.50 & 1.10 & 78.46 \\
\hline 20 & $2.958 \pm 0.012$ & $3.812 \pm 0.009$ & 6.770 & 0.93 & 0.53 & 1.11 & 77.55 \\
\hline 30 & $2.286 \pm 0.007$ & $3.780 \pm 0.010$ & 6.066 & 0.81 & 0.56 & 1.12 & 76.89 \\
\hline 40 & $2.124 \pm 0.002$ & $3.381 \pm 0.005$ & 5.505 & 0.70 & 0.59 & 1.12 & 76.47 \\
\hline 50 & $1.800 \pm 0.001$ & $2.929 \pm 0.003$ & 4.729 & 0.59 & 0.62 & 1.12 & 76.12 \\
\hline 60 & $1.627 \pm 0.012$ & $2.671 \pm 0.009$ & 4.298 & 0.50 & 0.64 & 1.10 & 75.44 \\
\hline 70 & $1.397 \pm 0.011$ & $2.118 \pm 0.010$ & 3.515 & 0.42 & 0.67 & 1.06 & 73.54 \\
\hline 80 & $1.264 \pm 0.011$ & $1.950 \pm 0.012$ & 3.214 & 0.37 & 0.71 & 1.00 & 68.74 \\
\hline 90 & $1.618 \pm 0.009$ & $2.101 \pm 0.011$ & 3.719 & 0.28 & 0.75 & 0.94 & 58.65 \\
\hline 95 & $2.142 \pm 0.002$ & $2.469 \pm 0.007$ & 4.611 & 0.18 & 0.77 & 0.92 & 50.66 \\
\hline
\end{tabular}

\section{Solvent effects}

Results in Table 1 indicate that protonation constants of TPPS decrease with increasing concentration of DMF and reach to a minimum at $80 \%(\mathrm{v} / \mathrm{v})$, and then increase by further increasing the organic solvent. Two approaches were used for studying solvent effect on protonation of TPPS; Kamlet, Abboud and Taft (KAT) model and the Born's electrostatic model 
[26-29]. From a microscopic point of view, Abboud, Kamlet and Taft introduced some solvatochromic parameters to consider all modes of the solute-solvent interactions at molecular level [26-28]. Accordingly, parameters $\alpha, \beta$ and $\pi^{*}$ are defined as numerical representation of hydrogen bond donor acidity, hydrogen bond acceptor basicity and dipolarity-polarizability of the solvent respectively. Parameter $\pi^{*}$ is a reflection of nonspecific interactions, whereas $\alpha$ and $\beta$ include specific interactions. Each of specific (such as hydrogen bonding) and nonspecific (electrostatic) interaction has a linear contribution to the total solvation energies of solutesolvent interactions. Therefore in the framework of linear solvation energy relationships (LSER) concept, a multiparametric equation can be established to correlate the Gibbs free energy of solvent dependent phenomena with the KAT parameters. The general form of LSER equation is

$\log K=\mathrm{A}_{0}+\mathrm{a} \alpha+\mathrm{b} \beta+\mathrm{p} \pi^{*}$

where $A_{0}, a, b$, and $p$ are regression coefficients. $A_{0}$ is intercept whereas $a, b$ and $p$ quantify the sensitivity of $\log K$ values to acidity, basicity and dipolarity-polarizability of the solvent respectively.

Nonspecific electrostatic interactions can be studied by the Born model in a macroscopic point of view. This model is constructed entirely based on general electrostatic solute-solvent interactions. In this model solvent is considered as a continuum medium which its polarity can be solely described by its dielectric constant. If this model is correct, the plot of $\log K$ values versus the reciprocal dielectric constant of the media, $\varepsilon$, should be linear.

$\log K=(121.6 n / r)(1 / \varepsilon-0.0128)$

Where $r$ is the common radius of the ions and $n$ is the square summation of the charges involved in the protonation equilibrium.

To explain the effect of solvent on protonation of TPPS based on the KAT solvent parameters, $\log K_{1}, \log K_{2}$ and $\log K_{\mathrm{t}}$ values were correlated with solvent properties by means of multiple linear regressions analysis in Microsoft Excel program [30]. All of single, dual and multi-parameteric fitted equations were considered. However the number of parameters in the equation depends on the significance of the solute-solvent interactions. The $F$-statistic values were used to assess which of the LSER equations is statistically optimum model. The best predictive mathematical equation in the fitted models was obtained according to the highest $F$ statistic and smallest standard deviation values.

Correlation was not good when the percentage of DMF exceeds $80 \%(\mathrm{v} / \mathrm{v})$ in the mixtures. So, LSER equations were evaluated in $0-80 \%(\mathrm{v} / \mathrm{v})$ of DMF. The best fitted models are

$\log K_{2}=-0.43(0.16)+3.93(0.46) \alpha$

$r^{2}=0.91, F=72.97$

$\log K_{1}=10.15(0.54)-11.69(0.92) \beta$

$r^{2}=0.96, F=162.65$

$\log K_{\mathrm{t}}=0.46(0.14)+7.22(0.55) \alpha$

$r^{2}=0.96, F=170.24$

$F$ and $r^{2}$ are squared correlation coefficient and $F$-statistic values respectively. The number in bracket shows the standard deviation of each regression coefficient. This result indicates that the protonation of TPPS is mainly dependent on specific solute-solvent interactions in water-DMF mixtures. The single-parameter KAT equation including $\alpha$ is the best for $\log K_{2}$. The positive sign of $\alpha$ term indicates that a decrease in the hydrogen-bond donor acidity capability of the solvent decreases the solvation tendency of the produced anions. Consequently, the $\log K_{2}$ decreases with decreasing values of this parameter. In the case of $\log K_{1}$, best fitted model includes only $\beta$ term. The regression coefficient of $\beta$ has a negative sign which means an 
increase in hydrogen bonding basicity of the mixture decreases $\log K_{1}$. It is interesting that the overall protonation constant of TPPS, $\log K_{\mathrm{t}}$, is mainly affected by $\alpha$ term similar to $\log K_{2}$. As mentioned above, protonation constants increase in the percentage of $80-95 \%(\mathrm{v} / \mathrm{v})$ of DMF. Due to little experimental data in these ranges, protonation constants were correlated only with one KAT parameter. The best fitted models were obtained as

$\log K_{2}=2.96(0.11)-4.63(0.36) \alpha$

$r^{2}=0.99, F=151.9$

$\log K_{1}=2.93(0.17)-2.75(0.58) \alpha$

$r^{2}=0.96, F=22.79$

$\log K_{\mathrm{t}}=5.89(0.27)-7.38(0.95) \alpha$

$r^{2}=0.98, F=60.16$

Protonation constants TPPS are affected by $\alpha$ term in $80-95 \%(\mathrm{v} / \mathrm{v})$ of DMF. However, $\alpha$ has negative value in all cases; indicating the increase of protonation constant with decreasing acidity of the solvent. The observed different solvent effect on different regions may relate to the structural change of binary mixtures due to solvent-solvent interactions and possibility of preferential solvation.

It is interesting to verify the effect of nonspecific interactions by analyzing data with the Born's electrostatic model [29, 31]. Born's model was examined by plotting protonation constant as a function of the reciprocal dielectric constant of the mixture in Figure 5.

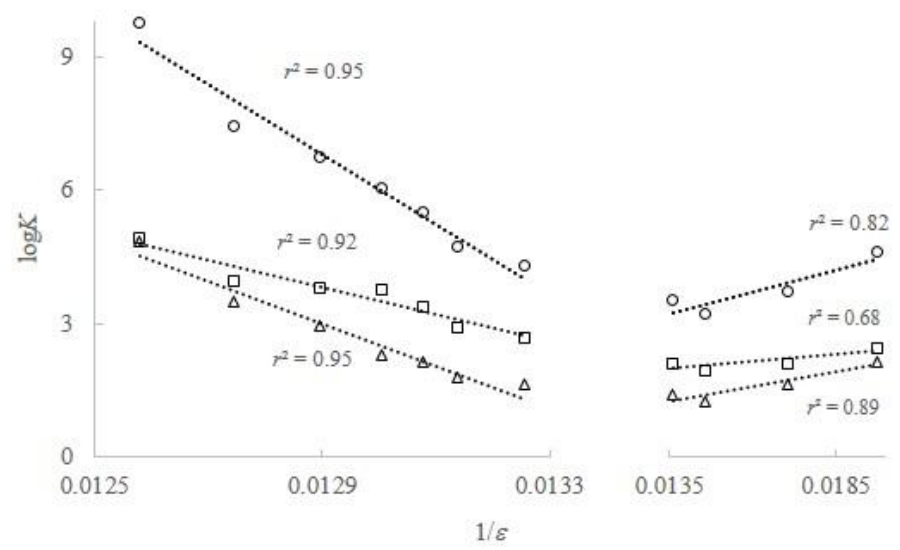

Figure 5. The plot of $\log K_{\mathrm{t}}(\mathrm{o}), \log K_{1}(\square)$ and $\log K_{2}(\Delta)$ versus the reciprocal dielectric constant of different water-DMF mixtures at $25^{\circ} \mathrm{C}$ and $0.1 \mathrm{~mol} \cdot \mathrm{dm}^{-3} \mathrm{NaClO}_{4}$.

In experimental range, $0-60 \%(\mathrm{v} / \mathrm{v})$ DMF, a linear correlation was obtained in accordance with Born's model; indicating that protonation constant of TPPS decreases with decreasing polarity of the mixture. The slope of plots is related to the term $n$ in Eq. 6. For first, second and overall protonation equilibria, $n$ is $-8,-6$ and -10 , respectively. Negative sign of $n$ indicates that species on the left-hand side of reactions are more polar than those on the other side. Therefore, one expects instead an increase of protonation constant by the lowering dielectric constant, which is not consistent with the theoretical basis of Born's model. Manifestly in accord with KAT model, this result indicate that protonation of TPPS was not only depended on the electrostatic interactions but also strongly depended on the specific solute-solvent and solventsolvent interactions. 


\section{CONCLUSION}

In this work, protonation constants of TPPS were successfully determined in wide organic concentration range of aqueous solutions of DMF $0-95 \%(\mathrm{v} / \mathrm{v})$ at $25{ }^{\circ} \mathrm{C}$ and $0.1 \mathrm{~mol} . \mathrm{dm}^{-3}$ sodium perchlorate. Although the polarity of media decreases with increasing DMF in solution, Born's model examination indicates that the non-specific electrostatic solute-solvent interactions have a doubtful effect in 0-60 \% (v/v) DMF. Considering Kamlet-Taft parameters in the framework of linear solvation energy relationship concept, in $0-80 \%(\mathrm{v} / \mathrm{v}) \mathrm{DMF}$, the main contribution to $\log K_{1}$ and $\log K_{2}, \log K_{\mathrm{t}}$ was found to be from $\beta$, and $\alpha$, respectively. In DMFrich regions, $\alpha$ was the most significant parameter of solvent effect on protonation constant of TPPS.

\section{ACKNOWLEDGMENTS}

The authors gratefully acknowledge the financial support from the Research Council of Islamic Azad University Jouybar branch.

\section{REFERENCES}

1. Longo, F.R.; Brown, E.M.; Rew, W.; Adler, A.D. The Porphyrins, Academic Press: New York; 1980.

2. Lavallee, D.K. Coord. Chem. Rev. 1985, 61, 55.

3. Winkelman, J. Cancer Res. 1969, 22, 589.

4. Hambright, P.; Kadish, K.M.; Smith, K.M.; Guilard, R. The Porphyrin Handbook, Vol. 3, Academic Press: New York; 2000.

5. Mosinger, J.; Deumie, M.; Lang, K.; Kubat, P.; Wagnerova, D.M. J. Photochem. Photobiol. A: Chem. 2000, 130, 13.

6. Bohmer, R.M.; Mortyson, G. Cancer Res. 1985, 45, 5328.

7. Moan, J.; Peng, Q.; Evensen, J.F.; Berg, K.; Western, A.; Rimington, C. Photochem. Photobiol. 1987, 46, 713.

8. Cunderlikova, B.; Gangeskar, L.; Moan, J. J. Photochem. Photobiol. B: Biol. 1999, 53, 81.

9. Tannock, I.F.; Rotin, D. Cancer Res. 1989, 49, 4373.

10. Engst, P.; Kubat, P.; Jirsa, M. J. Phochem. Photobiol. A: Chem. 1994, 78, 215.

11. Brunner, H.; Arndt, M.R.; Treittinger, B. Inorg. Chim. Acta 2004, 357, 1649.

12. Farajtabar, A.; Gharib, F.; Jamaat, P.; Safari, N. J. Chem. Eng. Data 2008, 53, 350.

13. Farjtabar, A.; Gharib, F. J. Solution Chem. 2010, 39, 231.

14. Gharib, F.; Soleimani, F.; Farajtabar, A.; Aghaei, H. J. Chem. Eng. Data 2009, 24, 2060.

15. Naderi, F.; Farajtabat, A.; Gharib, F. J. Solution Chem. 2012, 41, 1033.

16. Gharib, F.; Shamel, A.; Jaberi, M.; Farajtabar, A. J. Solution Chem. 2013, 42, 1083.

17. Jaberi, F.; Gharib, F.; Farajtabar, A. J. Solution Chem. 2013, 42, 1559.

18. Samadi, N.; Salamati, N. Bull. Chem. Soc. Ethiop. 2014, 28, 373.

19. Gamov, G.A.; Khokhlova, A.Y.; Gushchina, A.S.; Grazhdan, K.V.; Sharnin, V.A. J. Chem. Thermodynamics 2016, 97, 322.

20. Sheng-Yun, L.; Yu-Cui, H. Bull. Chem. Soc. Ethiop. 2014, 28, 187.

21. Beltran, J.L.; Codony, R.; Prat, M.D. Anal. Chim. Acta 1993, 276, 441.

22. Gran, G. Analyst 1952, 77, 661.

23. Egawa, Y.; Hayashida, R.; Anzai, J. Langmuir 2007, 23, 13146.

24. Marcus, Y. J. Chem. Soc. Perkin Trans. 1994, 2, 1751.

25. Wohlfarth, Ch. Static Dielectric Constants of Pure Liquids and Binary Liquid Mixtures, Springer-Verlag: Berlin; 1991.

26. Taft, R.W.; Abboud, J.L.M.; Kamlet, M.J. J. Org. Chem. 1984, 49, 2001.

27. Kamlet, M.J.; Abboud, J.L.M.; Abraham, M.H.; Taft, R.W. J. Org. Chem. 1983, 48, 2877.

28. Reichardt, C. Chem. Rev. 1994, 94, 2319.

29. Barbosa, J.; Barron, D.; Beltran, J.L.; Buti, S. Talanta 1998, 45, 817.

30. Billo, E.J. Excel for Chemists: A Comprehensive Guide, Wiley-VCH: Weinheim; 2001.

31. Rao, C.N.; Ramanaiah, M.; Sailaja, B.B.V. Bull. Chem. Soc. Ethiop. 2016, 30, 71. 